\title{
LA SOCIEDAD DEFENSA DE SEVILLA ARTÍSTICA Y SU LABOR DE SALVAGUARDA DEL PATRIMONIO HISTÓRICO SEVILLANO A COMIENZOS DEL SIGLO XX*
}

\author{
THE SOCIEDAD DEFENSA DE SEVILLA ARTÍSTICA \\ AND ITS WORK OF SAFEGUARDING OF SEVILLE'S \\ HISTORICAL HERITAGE AT THE BEGINNING OF THE \\ TWENTIETH CENTURY
}

\author{
Carmen de Tena Ramírez \\ Universidad de Sevilla. España \\ cdetena@us.es
}

\begin{abstract}
Con el presente artículo hemos querido dar a conocer y analizar la Sociedad Defensa de Sevilla Artística, agrupación de destacados miembros de la vida cultural sevillana de principios del siglo XX, surgida del interés por salvaguardar la fisonomía del barrio de Santa Cruz. Analizamos las campañas que lanzaron en pos de la conservación de algunos monumentos históricos sevillanos, y reflexionamos sobre la polémica que sus propuestas generaron en la ciudad, así como sobre los logros alcanzados gracias a las iniciativas que llevaron a cabo. Todo ello, atendiendo a los criterios de conservación monumental que plantearon y que destacaron por su carácter vanguardista.

Palabras clave: Sociedad Defensa de Sevilla Artística; urbanismo de Sevilla; conservación monumental; barrio de Santa Cruz; José Gestoso.

This paper tries to present and analyze the Sociedad Defensa de Sevilla Artística, a group of prominent figures of the Sevillian cultural life of the early twentieth century. This parnertship grew out of interest in safeguarding the urbanism of the Santa Cruz's neighborhood. Our research analyzes the campaigns started by their members, in order to preserve some Sevillian monuments. We reflect on the controversy that his proposals generated in the city, as well as achievements thanks to the initiatives undertaken. All this, according to the criteria of monumental conservation raised and highlighted by its avant-garde.

Keywords: Sociedad Defensa de Sevilla Artística; Seville’s Urbanism; Architectural and Urban Conservation; Santa Cruz's neighborhood; José Gestoso.
\end{abstract}

${ }^{*}$ Este trabajo ha sido realizado gracias a un contrato de formación predoctoral (Personal Investigador en Formación P.I.F.) del V Plan Propio de la Universidad de Sevilla. 
Los cambios en los usos y costumbres de las ciudades europeas entre los siglos XIX y XX, produjeron grandes cambios en la fisonomía de estas; en el caso de Sevilla, estos se vieron aumentados a causa de los estragos causados por contiendas políticas y sucesivas desamortizaciones, así como por el inevitable desarrollo de nuevos criterios urbanísticos y de saneamiento. Durante aquellos años, la mayor parte de la sociedad sevillana se mostró partidaria de apoyar las corrientes progresistas de planeamiento urbano, aún a costa de poner en serio peligro el legado monumental. Como respuesta a las sucesivas amenazas al patrimonio histórico-artístico sevillano, alzó la voz un grupo de intelectuales y artistas de gran influencia social, que tomó el nombre de Sociedad de Defensa de Sevilla Artística. Pero antes de hablar de esta agrupación y de su actividad, debemos presentar el contexto en el que surgió.

\section{ANTECEDENTES: LAS OBRAS DE ENSANCHE DEL BARRIO DE SANTA CRUZ}

La génesis de esta formación hay que buscarla en el año 1911; las obras de ensanche del barrio de Santa Cruz acapararon entonces toda la atención de la prensa sevillana. En los cafés, círculos y tabernas no se hablaba de otra cosa. Únicamente la muerte del político Joaquín Costa, logró eclipsar la encendida polémica que avivó las tertulias de la época.

Todo había comenzado pocos años atrás cuando el alcalde de Sevilla, Antonio Halcón y Vinent, se propuso llevar a cabo el plan de reformas que durante tanto tiempo la ciudad había exigido. Este se apoyaba en dos necesidades primordiales: mejorar la salubridad de los barrios y la accesibilidad de las vías de comunicación ${ }^{1}$.

El motor que impulsó el comienzo de las transformaciones urbanísticas fue, sin duda, el proyecto de la Exposición Iberoamericana que se gestó durante las primeras décadas del siglo XX. Realmente no se habían producido intervenciones urbanísticas de importancia desde el derribo de las murallas. No por falta de iniciativa, pues fueron muchos los proyectos planteados con el fin de reorganizar el espacio interior urbano, así como para establecer un plan de ensanche exterior.

${ }^{1}$ Sobre el urbanismo sevillano de comienzos del siglo XX, destacamos: GONZÁLEZ CORDÓN, Antonio: Vivienda y ciudad. Sevilla, 1848-1929. Sevilla, 1985; GONZÁLEZ DORADO, Antonio: Sevilla. Centralidad regional y organización interna de su espacio urbano (1900-1970). Sevilla, 2001; MARÍN DE TERÁN, Luis y DEL POZO SERRANO, Aurelio: Los pavimentos: un fragmento de la historia urbana de Sevilla. Sevilla, 1986; TRILLO DE LEYVA, Manuel: La Exposición Iberoamericana (1929-1930). La transformación urbana de Sevilla. Sevilla, 1980. VILLAR MOVELLÁN, Alberto: Arquitectura del Regionalismo en Sevilla. Sevilla, 1979. 
Desafortunadamente, el mal estado de las finanzas municipales obligó posponer las imprescindibles reformas.

Además de la necesidad de intervenir sobre la planta urbana de la ciudad, hubo que abordar los problemas de salubridad de los que adolecía, estando en su mayoría originados por la falta de una red adecuada de saneamiento y abastecimiento de agua. A esta circunstancia debemos añadir el pésimo estado en el que se encontraba una buena parte del caserío de la ciudad y por ende, las precarias condiciones de habitabilidad de muchas viviendas; los deficientes servicios de limpieza pública; la presencia de vertederos y cementerios en el núcleo urbano; así como la falta de pavimentación y acerado en la mayor parte del viario.

Al grave problema de salud pública que sufría Sevilla, se le añadió la premura por resolver los problemas de accesibilidad ocasionados por un aparentemente desordenado viario de calles estrechas y cortas que no se adaptaban a las exigencias del estilo de vida, teniendo que acoger un creciente número de grandes vehículos de transporte. Por todo ello fueron ideándose sucesivos proyectos de reforma y reordenación urbana ${ }^{2}$.

Estas circunstancias tan determinadas por las que se vio afectada la ciudad entre finales del siglo XIX y comienzos del XX, motivaron que fueran muchas las voces que se alzaran solicitando la intervención urgente del Ayuntamiento, y que este se ocupara de acometer un plan general de reformas urbanas.

Uno de los proyectos que desde hacía unos años solicitaba la población, fue el de apertura del barrio de Santa Cruz hacia la avenida de la Industria, actual Menéndez Pelayo. La extensión de jardines y huertas del Alcázar a lo largo de la zona sur del barrio, impedía la comunicación con el Prado de San Sebastián, y sólo la cesión de una parte de esos terrenos del Real Patrimonio, permitiría la apertura de nuevas vías, solucionando así un problema de aislamiento urbano por el que los vecinos de la zona se habían visto afectados durante mucho tiempo. Con esta apertura se buscaba, además, mejorar las condiciones higiénicas de este sector.

Fueron muchos los proyectos presentados desde 1884 para solicitar a la Casa Real la cesión de terrenos de la huerta del Alcázar, y así poder materializar el ensanche del barrio de Santa Cruz, en todos ellos, señalando su conveniencia esgrimiendo motivos de salubridad ${ }^{3}$. Finalmente, Real Patrimonio y el Ayuntamiento de Sevilla, acordaron la cesión de la Huerta del Retiro, haciéndose oficial en enero de $1911^{4}$. Poco antes, el ayudante del arquitecto municipal, Juan Talavera, ya se

${ }^{2}$ Remitimos de nuevo al lector a la bibliografía recomendada sobre el urbanismo sevillano de principios del siglo XX que hemos citado con anterioridad.

${ }_{3}$ Para conocer los diferentes proyectos planteados para acometer el ensanche del barrio de Santa Cruz, remito al lector a NIETO CALDEIRO, Sonsoles: El jardin sevillano de 1900 a 1929. Madrid, 1992, pp. 211-262.

${ }^{4}$ A.M.S. (Archivo Municipal de Sevilla), C.A. Huerta del Retiro y de la Alcoba, caja 448, exp. 174. Cesión por el Real Patrimonio de parte de la Huerta del Retiro. 
había encargado de realizar el proyecto de obras que debían de hacerse en la Huerta del Retiro con motivo de la cesión, remitido al Ayuntamiento el 26 de diciembre de $1910^{5}$ (Figura 1). Los terrenos cedidos por la Real Casa conformaban un triángulo que era atravesado por dos vías que partían, una desde la plaza de Alfaro y otra desde la de Santa Cruz, desembocando en el paseo de Catalina de Ribera ${ }^{6}$. Las cláusulas de la escritura de arrendamiento de los terrenos de la Huerta del Retiro al Ayuntamiento de Sevilla incluían la prohibición de levantar edificación alguna en su terreno, destinado exclusivamente a zonas ajardinadas.

La prensa no tardó en hacerse eco de la noticia, presentada por los medios liberales como un logro personal del alcalde, Antonio Halcón, anunciando que en pocas semanas darían comienzo las obras de apertura de las nuevas vías que permitirían la comunicación entre el barrio de Santa Cruz y el Prado de San Sebastián. Estas incluían la demolición de los trozos de muralla que cerraban las plazas de Santa Cruz y Alfaro y la tapia que limitaba la huerta por el Paseo Catalina de Ribera, obras de las que también se encargaba de sufragar el Ayuntamiento. A estas había que añadir el derribo de las casas número 4 y 5 de la plaza de Santa Cruz, necesario para abrir una de las nuevas vías?

\section{VOCES DISCORDANTES CON EL PROYECTO DE LA HUERTA DEL RETIRO: LA SOCIEDAD DEFENSA DE SEVILLA ARTÍSTICA}

Las reacciones en contra de esta reforma urbanística no se hicieron esperar. Hasta cuatro colectivos diferentes quisieron manifestar su desacuerdo con el proyecto de obras en la Huerta del Retiro. La primera llegó de la mano de "Unos artistas sevillanos", grupo que con dicho seudónimo dirigió una carta abierta al alcalde Antonio Halcón, publicada el día 26 de enero de 1911 en el periódico sevillano El Correo de Andalucía, y en la cual se solicitaba la paralización del proceso de enajenación y derribo de la casa número 4 de la plaza de Santa Cruz, necesario para llevar a cabo el proyecto de apertura de la nueva calle, ya que contaba,

${ }^{5}$ A.M.S. C.A. Huerta del Retiro y de la Alcoba, caja 448, exp. 174. Expediente formado para hacer las obras necesarias con motivo de la cesión de parte de la Huerta del Retiro por el Real Patrimonio y exp. 194. Expediente con proyecto de alineación para una nueva vía que comunique la plaza de Sta. Cruz con el prado de San Sebastián», cit. por NIETO, Sonsoles, El jardín sevillano..., op. cit., pp. 217-218.

${ }^{6}$ Nuevamente remitimos al lector al trabajo de NIETO CALDEIRO, Sonsoles: $E l$ jardín sevillano..., op. cit., pp. 217-231, quien documentó el proceso de cesión de la Huerta del Retiro, así como su urbanización por parte del Ayuntamiento de Sevilla, y el ajardinamiento de las zonas que permanecieron dentro del conjunto del Alcázar.

7 "El ensanche del barrio de Santa Cruz", en El Liberal (Sevilla), 3 de enero de 1911. 
al parecer, con valores estéticos que otorgaban al entorno el carácter de "precioso rinconcito netamente sevillano".

Pocos días después, un grupo de profesores de la Escuela de Bellas Artes e Industrias de Sevilla junto a algunos artistas, dirigieron al alcalde una carta solicitando que no se derribara la antigua muralla de la Huerta del Retiro para poner en comunicación el barrio de Santa Cruz con el Prado de San Sebastián, tal y como se había proyectado, sino que esta fuera íntegramente conservada y que en la embocadura de las dos nuevas vías se abrieran unas entradas en forma de arco de medio punto.

Mientras, la mayor parte de la opinión pública secundaba el proyecto del Ayuntamiento; tal fue el caso del periódico El Liberal (Sevilla), el cual, dirigió una feroz campaña en contra de la citada propuesta de conservación de la muralla y modo de efectuar las aperturas, arguyendo razones en línea con la necesidad de abrir el viario para satisfacer las necesidades que la circulación reclama en la zona. El propio alcalde, Antonio Halcón, con el fin de calmar los ánimos de aquellos que creían peligrar la integridad del barrio, quiso aclarar que el hecho de que se hubieran derribado algunas partes de la muralla de la Huerta del Retiro para abrir nuevas calles, no significaba que fuera a entrar en el barrio "la piqueta".

A esta petición, hay que sumar la moción presentada por el grupo conservador del Ayuntamiento, "proponiendo determinados acuerdos que tiendan a perpetuar el típico aspecto del barrio de Santa Cruz, mediante la conservación de sus actuales líneas, y la prohibición de que se construyan dentro de la zona que aquel comprende, edificios que alteren su peculiar estilo sevillano" ${ }^{0}$.

Por último, a estas tres iniciativas de protección urbanística del barrio de Santa Cruz, se les sumó la propuesta resultante de una reunión organizada por destacados personajes del mundo de la cultura y de la política sevillana. Estos señores se presentaron públicamente el 4 de febrero de 1911 en el Círculo de Labradores como una "sociedad de defensa del viejo Sevilla", anunciando que el objeto de dicha reunión era el de "trabajar en pro de la Sevilla artística, amenazada ahora de peligrosos cambios reformadores. Se refiere al barrio de Santa Cruz y a las obras que inmediatas al mismo se practican"11. En el acto comparecieron Carlos de la Lastra, Javier Sánchez Dalp, Gonzalo Bilbao, José Gestoso, Carlos Cañal,

8 "La reforma de la Huerta del Retiro" en El Liberal (Sevilla), 30 de enero de 1911.

${ }^{9}$ El Liberal (Sevilla), 6 de febrero de 1911.

10 A. M. S., Obras Públicas, 1911/15. "Expediente formado con motivo de la moción de varios Sres. Concejales y la solicitud de la Sociedad Sevillana de Amigos del Arte, para que no se realizen (sic) reformas en el barrio de Santa Cruz, que puedan alterar su carácter típico".

${ }^{11}$ El Liberal (Sevilla), 5 de febrero de 1911. 
Miguel [Anibal] G. Álvarez Ossorio ${ }^{12}$, José García Ramos, Manuel Cano y Cueto, Mariano González Rojas, Cayetano Sánchez Pineda, Fernando Reinoso, Gabriel Lupiañez, José Pando y Virgilio Mattoni, excusando su ausencia Pitaluga, Simón Barris, Pagés y Belloc, D’Angelo, Gómez Otero y Miguel Sánchez Dalp.

Para poder valorar en su justa medida el interés de esta reunión, hay que tener en cuenta que los anteriormente citados, como es bien conocido, eran todos ellos personajes destacados de la Sevilla de principios del siglo XX, y en su mayoría pertenecientes a sus instituciones culturales más afamadas, como el Ateneo y las Reales Academias. A continuación presentamos una breve reseña biográfica de esta "sociedad de defensa del viejo Sevilla", sin la pretensión de extendernos demasiado ${ }^{13}$.

Carlos de la Lastra, marqués de Torrenueva, además de ser un destacado miembro de la aristocracia sevillana, fue miembro del Partido Conservador, en el que desempeñó diversos cargos. También fue director de la Real Academia de Bellas Artes entre 1899 y 1925.

Los hermanos Sánchez-Dalp, Javier y Miguel, protectores y mecenas de las bellas artes, y amigos de Alfonso XIII, también quisieron apoyar esta iniciativa. Javier fue político del Partido Conservador, senador del reino y, al igual que su hermano, promotor de la arquitectura regionalista sevillana. Miguel contribuyó al desarrollo del empresariado agrícola y ganadero sevillano, a la vez que dedicaba gran parte de su tiempo a obras filantrópicas.

Virgilio Mattoni, José García Ramos, Gonzalo Bilbao y José de Pando fueron respetados y valorados pintores de la ciudad. Mattoni y Bilbao fueron además vocales de la Comisión Provincial de Monumentos Histórico-Artísticos de Sevilla, donde desarrollaron una intensa actividad.

El afamado historiador José Gestoso y Pérez destacó durante toda su vida como un firme defensor de la protección del patrimonio monumental, siendo muy crítico públicamente con las intervenciones encaminadas a su destrucción.

Carlos Cañal, político perteneciente al Partido Conservador, llegó a ser ministro durante el reinado de Alfonso XIII, ocupando distintas carteras. Incluso desempeñando tan destacados cargos, tuvo tiempo para dedicarse al estudio de la incipiente ciencia arqueológica y para participar activamente en diversas instituciones culturales sevillanas.

${ }^{12}$ El texto original recoge el nombre de Miguel G. Álvarez Ossorio, siendo sin duda un error del autor de la noticia, pues en posteriores artículos periodísticos aparece el nombre real: Aníbal.

${ }^{13}$ Los datos biográficos han sido recogidos fundamentalmente de: AA.VV., Diccionario de ateneistas. Sevilla, 2004; CASCALES Y MUÑOZ, José: Sevilla intelectual, sus escritores y artistas contemporáneos. Madrid, 1896; MÉNDEZ BEJARANO, Mario: Diccionario de escritores, maestros y oradores naturales de Sevilla y su actual Provincia. Sevi1la, 1922-25. 
El literato Manuel Cano y Cueto fue miembro de instituciones culturales sevillanas como el Ateneo, del que llegó a ser presidente, y de la Real Academia de Buenas Letras de Sevilla. También es destacable su actividad política como gobernador civil y diputado. También diputado en el Congreso, por Sevilla, y presidente del Ateneo, lo fue Estanislao D'Angelo, catedrático de Derecho de la Escuela de Comercio.

Los arquitectos Aníbal González Álvarez-Ossorio, Mariano González Rojas, Simon Barris y José Gómez Otero no quisieron dejar de apoyar esta causa. Supieron combinar su práctica profesional, adoptando en ocasiones las nuevas corrientes modernistas y regionalistas, como fue el caso de Aníbal González, con el respeto por la riqueza monumental de Sevilla.

No faltaron en la reunión grandes personajes del mundo académico sevillano, a saber, Fernando Reinoso, catedrático de Latín y Castellano del Instituto de Sevilla; Vicente Pitaluga, director de la Escuela de Bellas Artes e Industrias; Francisco Pagés y Belloc, catedrático de la Facultad de Letras de la Universidad de Sevilla de la cual llegó a ser rector entre 1909 y 1917; y el médico Gabriel Lupiáñez Estévez, catedrático de Patología Médica en la Escuela Provincial de Medicina y también nombrado rector de la Hispalense en 1917.

A todos ellos hay que sumar al académico Cayetano Sánchez Pineda, quien llegó a ser director del Museo de Bellas Artes de Sevilla, tras su escisión de la Real Academia en 1925.

Sirvan estas sencillas notas para ponderar el peso que tuvieron todos estos personajes en la sociedad hispalense, la gran influencia que ejercieron en su momento, y por tanto, el elevado alcance de sus declaraciones.

Retomando la citada reunión, las propuestas emanadas se centraron en dos puntos. El primero fue la necesidad de constituir entre los asistentes "una Sociedad de defensa del viejo Sevilla", nombrando una comisión para estudiar la manera de proceder y de elaborar un reglamento. Por otro lado, acordaron la redacción de una solicitud dirigida al alcalde Antonio Halcón, incluyendo una serie de propuestas enfocadas a la conservación de la fisonomía del barrio de Santa Cruz. Este texto comenzaba con la adhesión de los firmantes a la moción anteriormente citada, presentada por el grupo conservador del cabildo sevillano, que recordemos solicitaba la petición de un régimen de protección especial a la zona, entendiendo como tal el área comprendida entre los siguiente límites: "al SE, por las antiguas murallas de la Huerta del Retiro. Por el NE, por la calle Santa María la Blanca ( sin comprender ésta). Por el NO, por las calles Farnesio, Fabiola y Mateos Gago (tampoco comprendida) y por el SO, por el Alcázar, Patio de Banderas y plaza del Triunfo", sin que con ello se considerara argumento alguno vinculado a la estructura urbana o a su origen histórico. Igualmente, esta protección era extensible a la fisonomía del caserío, solicitando que "no se consentirá en las fincas comprendidas en el perímetro de la zona mencionada ejecutar obras totales o parciales de construcción o reforma que sean de carácter modernista o que alteren el 
clásico o peculiar estilo sevillano que dichas casas tienen", teniendo que ser supervisadas y autorizadas las obras de particulares por la Real Academia de Bellas Artes de Sevilla. La petición exigía que este acuerdo fuera incluido en las ordenanzas municipales de la ciudad, siendo la Comisión de Obras Públicas garante de su efectividad legal y material.

Resulta digno de considerar el carácter novedoso de esta solicitud al Ayuntamiento, ya que supone un hito dentro de la historia de la protección del patrimonio histórico sevillano. Los centros históricos no contaron con las primeras medidas legislativas y normativas de protección hasta mediados del siglo XX, momento en el que se toma conciencia de su propia realidad ${ }^{14}$. No obstante, tal y como nos demuestra el caso que analizamos, existen antecedentes que demuestran la preocupación por la salvaguarda de la ciudad histórica.

Por otro lado, insistieron en la conservación de la antigua muralla de la Huerta del Retiro, tal y como ya habían demandado algunos de los firmantes previamente en la ya citada carta abierta del grupo de profesores de la Escuela de Bellas Artes e Industrias y algunos artistas, publicada el 1 de febrero de 1911 El Liberal, solicitando, nuevamente, que la apertura de las entradas que establecieran la comunicación con el barrio de Santa Cruz, se hicieran "en forma de arcos, con sus marmolillos y cadenas, que indique claramente que es paso exclusivo de peatones", petición que demuestra la intención de evitar el tráfico rodado por sus calles, a sabiendas de los perjuicios que este podría ocasionar en el caserío.

Novedoso fue también el interés por mantener la configuración de los terrenos donados por la Real Casa, solicitando que se conservaran "las desigualdades del terreno, así como también sus añosos árboles", es decir, abogando por un urbanismo de estética romántica, en la que se ponderan los valores artísticos de la naturaleza sin imposiciones formales, gustando de conservar los accidentes del terreno con presencia abundante de arbustos y malezas. Esta idea de espacio de naturaleza urbana, choca frontalmente con los proyectos que se ejecutaban coetáneamente en Sevilla durante principios del siglo XX, concretamente con los del paisajista francés Jean-Claude Nicolas Forestier en el parque de María Luisa, en cuyo diseño tendió al orden y geometrización de las trazas.

La solicitud presentada al alcalde finalizaba con la sugerencia de "comunicar la plaza de Alfaro con la calle Muro del Agua [actual calle Agua] interrumpida ahora por varias fincas que apoyan en la muralla, formando en la planta baja de las mismas una calle techada con la disposición característica".

Si bien la reunión se centró en la preservación del barrio de Santa Cruz, se acordó igualmente presentar al alcalde otra propuesta referente a las murallas de la Macarena, recientemente mutiladas para abrir unos portillos que permitieran la comunicación de los barrios de San Julián y de Santa Lucía con la actual ronda

${ }^{14}$ GONZÁLEZ-VARAS, Ignacio: Conservación de bienes culturales. Teoría, historia, principios y normas. Madrid, 2008, p. 144. 
de Capuchinos. De la misma forma que en el caso de la muralla de la Huerta del Retiro, el objetivo era que estas aperturas adoptaran forma de medio punto.

Esta solicitud, en la que finalmente se optó por no incluir aspecto alguno referente a las murallas de la Macarena, fechada en Sevilla el 4 de febrero de 1911, venía firmada por la Sociedad de Amigos del $\mathrm{Arte}^{15}$, nombre que tomó el grupo de intelectuales, políticos y artistas del que hemos hablando ${ }^{16}$. Fue entregada al alcalde Antonio Halcón el 7 de febrero de 1911, pero ya había comenzado a generar una encendida polémica entre la población sevillana tras publicarse días antes los acuerdos tomados para su elaboración, sucediéndose duras críticas a la propuesta de la Sociedad y a sus postulantes y defensores. La prensa local, especialmente El Correo de Andalucía y El Liberal (Sevilla), se hizo eco de la pugna existente entre las opiniones vertidas por los simpatizantes de la conservación del barrio y los de su "saneamiento".

Desde luego, las propuestas de la llamada Sociedad de Amigos del Arte no calaron entre los vecinos del barrio afectado. Tal y como podemos apreciar gracias a fuentes hemerográficas, entre ellos abundaba un tremendo descontento a causa del estado en el que, al parecer, se hallaba el barrio, caracterizado más por "montones de basura, pedreas, pisos intransitables, calles y casas malolientes y la incuria y el abandono" que por ser "típico y artístico", aduciendo que eran contrarios al "espíritu regresivo y reaccionario de dichos señores, que, en nombre del arte pretenden que vivamos como en el siglo XIII"17. El descontento entre los habitantes de Santa Cruz creció hasta tal punto que una comisión de vecinos, presidida por el teniente de alcalde del segundo distrito, González Fragoso, organizó una manifestación ante el Ayuntamiento con el fin de protestar oficialmente contra la moción de los conservadores del Ayuntamiento y la solicitud acordada por la Sociedad de Amigos del Arte, referente a las obras de ensanche del barrio. Fueron recibidos por Antonio Halcón y le manifestaron el deseo de que las entradas al barrio fueran amplias, que se permitiera hacer las reformas "en sentido moderno, ensanchando las calles y obrando casas modernas, con todas las condiciones de higiene posibles" ${ }^{18}$.

La moción presentada por el grupo conservador del Ayuntamiento de Sevilla, apoyada por la solicitud de la Sociedad Amigos del Arte para proteger las líneas del barrio de Santa Cruz y preservar su fisonomía, fue debatida en sesión

${ }^{15}$ Este nombre fue modificado por otro más ajustado en cuanto a su finalidad se refiere, Sociedad Defensa de Sevilla Artística, tal y como después explicaremos.

16 A.M.S., Obras Públicas, 1911, exp. 15. "Expediente formado con motivo de la moción de varios Sres. Concejales y la solicitud de la Sociedad Sevillana de Amigos del Arte, para que no se realizen (sic) reformas en el barrio de Santa Cruz, que puedan alterar su carácter típico".

${ }_{17}$ El Liberal (Sevilla), 6, 8, 9, 10, 14 de febrero de 1911.

${ }_{18}$ El Liberal (Sevilla), 9 de febrero de 1911. 
municipal de 17 de febrero de 1911, levantando no poca expectación ${ }^{19}$. Anteriormente, la Comisión de Obras Públicas ya se había pronunciado al respecto desestimándola, en base a que "se procurará siempre con preferente atención cuanto tienda a mejorar la Ciudad, embelleciéndola, saneándola, y ensanchándola, conforme lo reclaman las necesidades de su población, al desenvolvimiento y desarrollo de su comercio y sus industrias, y la importancia de su tráfico, por la prosperidad de su puerto".

Una vez abierto el debate sobre el dictamen, se valoraron las opiniones vertidas en prensa por los vecinos del barrio, en contra de la conservación de las actuales líneas y sí a favor de un proyecto de ensanche que reportara «sol, aire, ventilación, higiene en una palabra», ya que, eran muchos los que habían demostrado sobradamente que en él no había nada de artístico ${ }^{20}$. Muy destacada fue la intervención del edil conservador Solís Desmaissieres, concluyendo que la salubridad del barrio de Santa Cruz no dependía de ensanches, y sí de higienizar convenientemente las viviendas, y que por tanto no era necesario llevar a cabo "ensanches ni obras que modifiquen la estructura del barrio, que encierra bellezas artísticas y un encanto especial que aman los amantes sevillanos de lo tradicional". Finalmente, esta moción fue desestimada ${ }^{21}$.

\section{ACTIVIDAD DE LA SOCIEDAD DEFENSA DE SEVILLA ARTÍSTICA}

A tenor de los datos documentales hallados en al Archivo Municipal de Sevilla y las noticias que ofrece la prensa de la época, podemos asegurar que las reuniones de la citada Sociedad Amigos del Arte se celebraron desde el 4 de febrero de 1911 hasta, al menos, el 7 de julio de 1911.

Ya hemos hablado de la primera reunión celebrada por este grupo de personalidades el 4 de febrero de dicho año. Después de que se debatiera en sesión municipal la moción sobre la conservación del barrio de Santa Cruz, se convocó una nueva junta semanas más tarde, el 20 de febrero, con objeto de tratar asuntos

19 A.M.S., Sección X, Actas capitulares de 1911. Sesión ordinaria del 17 de febrero de 1911.

${ }^{20}$ El concejal González Fragoso incluso llegó a hacer referencia de la célebre obra de José Gestoso, Sevilla monumental y artística, en la que no se mencionaba al barrio de Santa Cruz, para demostrar que carecía de todo interés histórico-artístico.

${ }^{21}$ Años más tarde, el barrio de Santa Cruz fue objeto de una remodelación urbana más epidérmica que estructural, dirigida por la Comisaría Regia de Turismo, y especialmente por su máxima autoridad, el marqués de la Vega-Inclán. Esta intervención le confirió su imagen actual, cuyos valores artísticos, que en cierta forman adolecen de un regusto tipista, entusiasman al visitante foráneo. Al respecto, merece destacarse el estudio de: MENÉNDEZ ROBLES, María Luisa. La huella del marqués de la Vega Inclán en Sevilla. Sevilla, 2008. 
relacionados con la constitución de la Sociedad de Amigos del Arte ${ }^{22}$. En primer lugar se dio lectura al reglamento de la misma, en el que constaba que el objeto de la sociedad era "la defensa de todos los intereses artísticos e históricos de Sevilla, a fin de prevenirlos en cuanto en su menoscabo se intenta por la Corporación y particulares". Una vez discutido, se decidió que dicho reglamento se presentara inmediatamente en el Gobierno Civil. Miguel Sánchez-Dalp ofreció como domicilio social su casa particular, detalle que mereció el agradecimiento de los concurrentes.

Una vez atendidos los procedimientos burocráticos necesarios, la reunión se centró en proponer los primeros trabajos a los que se iba a dedicar la Sociedad, exponiendo "la conveniencia de trabajar con actividad por la conservación de varios monumentos como la torre de D. Fadrique y la de San Marcos".

La torre de San Marcos se encontraba en estado de ruina desde hacía ya varios años, tal y como denunció en 1903 José Gestoso, quien al ser nombrado vicepresidente de la Comisión Provincial de Monumentos, pretendió declarar Monumento Nacional la torre de la iglesia de San Marcos, para poder atender a su restauración ${ }^{23}$. De hecho, nada pudo hacerse hasta 1916, año en el que fue intervenida por el arquitecto Aníbal González, con el asesoramiento del propio Gestoso, gracias a la financiación ofrecida por el conde de Urbina.

Por otro lado, la torre de D. Fadrique no sólo se veía afectada entonces por la amenaza de ruina, sino que existía el temor creciente a que las monjas del convento de Santa Clara, que acuciadas por graves problemas económicos estaban vendiendo parcelas de su huerta, pusieran en venta el terreno donde se halla la construcción. De ser adquirida por un particular, esta podría exponerse a transformaciones o incluso a su desaparición. Ya fueron advertidas de esta circunstancia en 1905 la Real Academia de Bellas Artes de San Fernando, y en 1906 la Real Academia de la Historia, a las cuales se dirigió la Comisión Provincial de Monumentos de Sevilla solicitando su apoyo para que se declarara Monumento Nacional la torre, y por tanto, se viera liberada del riesgo de la venta ${ }^{24}$, petición

${ }^{22}$ El Liberal (Sevilla), 21 de febrero de 1911, cit. por RODRÍGUEZ AGUILAR, Inmaculada C.: Arte y cultura en la prensa: la pintura sevillana (1900-1936). Sevilla, 2000, p. 87 y PÉREZ CALERO, Gerardo: Las Bellas Artes y el Ateneo de Sevilla. La vida artística de la ciudad (1887-1950). Sevilla, 2006, vol. I, pp. 163-164.

${ }^{23}$ El Liberal (Sevilla), 2 y 14 de abril de 1911, cit. por Rodríguez, Inmaculada C.: Arte y cultura en la prensa..., op. cit., p. 83; nada se menciona al respecto en la obra de López Rodríguez, Raquel M.: La Comisión de Monumentos Históricos y Artísticos de la provincia de Sevilla. Sevilla, 2011; no se conserva documentación acerca de esta iniciativa ni en la Real Academia de Bellas Artes de San Fernando ni en la Real Academia de la Historia.

${ }^{24}$ A.R.A.B.A.S.F. (Archivo de la Real Academia de Bellas Artes de San Fernando), sign. 4-40-2, leg. 1, exp. 26; C.A.R.A.H. (Comisión de Antigüedades de la Real Academia de la Historia), sign. CASE/9/7971/058. Recordemos que en estos momentos, y desde 1903 hasta 1917, José Gestoso fue el vicepresidente de la Comisión Provincial de Monumentos 
reiterada en $1911^{25}$. Mientras el proceso burocrático discurría con lentitud, José Gestoso publicaba un artículo en El Correo de Andalucía, pocos días después de la reunión del 20 de febrero de la Sociedad Amigos del Arte, en el cual proponía que el Ayuntamiento de Sevilla adquiriese a las monjas de Santa Clara el terreno en el que se hallaba la torre ${ }^{26}$. La propuesta lanzada por Gestoso, se materializó años después, el 28 de diciembre de 1918, fecha en la que, efectivamente, fue adquirida por el Ayuntamiento ${ }^{27}$. Muchos más años tardó en llegar la declaración de Monumento Nacional, el 3 de junio de $1931^{28}$.

La siguiente reunión de los Amigos del Arte se celebró el 9 de marzo de 1911, de nuevo en el sevillano Círculo de Labradores ${ }^{29}$, aunque en esta ocasión, adoptando un nombre distinto, Sociedad Defensa de Sevilla Artística ${ }^{30}$. Con esta denominación fue, al parecer, presentado su correspondiente reglamento en el

de Sevilla, y también formaba parte de la Sociedad Amigos del Arte, igual que otros miembros de dicha Comisión, tales como Gonzalo Bilbao, Virgilio Mattoni, Fernando Reinoso o José García Ramos.

25 A.R.A.B.A.S.F., sig. 5-168-5, exp. 2, "La Comisión provincial de Monumentos de Sevilla ruega a la Academia interponga su valimiento y eficacia con el Sr. Ministro de Instrucción Pública para que sea expedida la Real Orden declarando Monumento Nacional la histórica torre de D. Fadrique, único medio de salvar su existencia amenazada por una próxima venta de la misma". La solicitud firmada por José Gestoso está fechada el 16 de febrero de 1911; por su parte, la Real Academia de Bellas Artes de San Fernando intervino el 28 de abril del mismo año mandando comunicación al Ministerio, solicitando la ansiada declaración.

${ }^{26}$ (...) ¿no sería patriótico, culto y merecedor de unánime aplauso que nuestro Ayuntamiento adquiriese la parcela en que se halla la torre y dejándole alrededor una separación suficiente para que sea bien vista estableciendo en esta un jardín rodeado de verja?, "El torreón de Don Fadrique", en El Correo de Andalucía, 22/02/1911. Este artículo se ha conservado en el Gabinete de Antigüedades de la Real Academia de la Historia con la signatura CASE/9/7971/058(5).

27 A.M.S. Obras Públicas, 1918, exp. 115.

${ }^{28}$ Real Decreto de 3 de junio de 1931, La Gaceta de Madrid, 04/06/1931.

29 "Sociedad de Defensa Artística", en El Liberal (Sevilla), 11/03/1911.

${ }^{30}$ El cambio de nombre estaría motivado por dos circunstancias, la primera que durante estos mismos años funcionaba en Madrid la Sociedad española de Amigos del Arte, institución vinculada a la aristocracia y la alta burguesía madrileña y española, creada en 1909 por dña. Trinidad de Scholtz-Hermensdorff de Iturbe, con el propósito de difundir el patrimonio artístico español, cf. ALAMINOS LÓPEZ, Eduardo: "Los museos locales y el Museo Municipal de Madrid", Boletín de la ANABAD, t. 47, 2, 1997, p. 133, cit. de MATEOS PÉREZ, Prudencio: "La Sociedad Española de Amigos del Arte", Villa de Madrid, 94, 1987, pp. 70-86. La segunda, que ya existía en Sevilla una sociedad llamada Los Amigos del Arte, fundada "para el fomento de la Literatura, la Música y el Arte Escénico", cf. Pérez Calero, Gerardo: Las Bellas Artes y el Ateneo de Sevilla... op. cit., p. 164. En definitiva, se adoptó el nuevo nombre Sociedad de Defensa de Sevilla Artística para no inducir a confusión. 
Gobierno Civil, donde fue aprobado ${ }^{31}$. Una vez abierta la sesión, de llevó a cabo el nombramiento de la junta directiva, siendo constituida de la siguiente forma: presidente, Javier Sánchez-Dalp; vicepresidentes: Manuel de Torres y Gonzalo Bilbao; secretarios: primero, Cayetano Sánchez Pineda; segundo Julio del Mazo y Franza; consiliarios: duque de T’Serclaes, marqués de Torrenueva, José Gestoso, conde de Aguiar, Manuel Cano y Cueto y Gabriel Lupiáñez.

Tras constituir la junta directiva, la Sociedad, se propuso comenzar a emprender "las gestiones oportunas a favor de los monumentos artísticos y arqueológicos que reclaman su interés", acordando ir a visitar al alcalde Antonio Halcón, para tratar acerca de las murallas de la Macarena, la capilla de San José y la iglesia de Santa Catalina ${ }^{32}$.

Ya hemos hecho señalado los desvelos de la Sociedad por la conservación del lienzo de murallas conservado entre la Puerta de Córdoba y el Arco de la Macarena, fundamentados en la apertura de unos portillos en la misma con el pretexto de dar salida al tráfico de los barrios de San Julián y Santa Lucía. José Gestoso, como vicepresidente de la Comisión Provincial de Monumentos, se encargó personalmente de rediseñar las citadas aperturas, de forma que no atentaran tan gravemente contra la estética del monumento ${ }^{33}$. Por otro lado, la capilla de San José y la iglesia de Santa Catalina, estuvieron al borde de la desaparición a causa de los nuevos ensanches proyectados en Sevilla a comienzos del siglo XX, concretamente, el de la calle Jovellanos y el de la calle Alhóndiga, respectivamente. Nuevamente, la Comisión Provincial de Monumentos, intervino activamente en la obtención de la declaración de Monumento Nacional mediante Real Orden de 5 de septiembre de $1912^{34}$.

Una vez establecidas estas líneas de actuación ${ }^{35}$, se acordó que, una vez constituida la Sociedad, se solicitara audiencia al rey para presentársela y ofrecerle la presidencia honoraria. Igualmente, se acordó repartir hojas de adhesión a la sociedad para que se inscribieran en ellas aquellos interesados en figurar en la misma $^{36}$.

31 Sin embargo, no consta que fuera inscrita en el Libro de Registro del Gobierno Civil de Sevilla durante el año 1911.

${ }^{32}$ No debemos dejar pasar por alto la circunstancia de ser algunos de los miembros de la Comisión Provincial de Monumentos. Sin duda, este hecho debió beneficiar el contacto entre ambos entes, y repercutiendo por tanto en su capacidad de actuación.

33 Esta intervención sobre la muralla, así como la pugna que ocasionó entre la Alcaldía y la Comisión Provincial de Monumentos de Sevilla, ha sido documentada y estudiada por López, Raquel M., La Comisión de Monumentos..., op. cit., pp.140-144.

${ }^{34}$ Ibídem, pp. 151-152.

${ }_{35}$ No hemos encontrado documentación que atestigüe la intervención de la Sociedad en la salvaguarda de estos tres monumentos.

${ }^{36}$ Entre los papeles personales de uno de los miembros de la Sociedad, José Gestoso, se conserva una de aquellas cartas de adhesión: B.C.C. (Biblioteca Capitular y Colombina), 
La siguiente reunión de la Sociedad se celebró el 16 de marzo de 1911, fruto de la cual se ha conservado una instancia dirigida al alcalde Antonio Halcón y a la corporación municipal, fechada el 7 de abril de dicho año ${ }^{37}$. En ella se solicitaban dos intervenciones muy precisas. La primera atañía a las columnas del solar de la calle Mármoles, pidiendo que fuera objeto de arreglo "de manera que quede al descubierto, por lo menos la totalidad de una de ellas con su basamento; armonizando, a ser posible, esta obra que permitiría estudiar mejor el monumento, con la salida natural de las aguas que habían de acumularse necesariamente dado el desnivel del terreno"; solicitando además que se sustituyera la actual verja, al parecer en mal estado, "por otra todo lo más sencilla posible". En segundo término se instaba a la corporación municipal a que se cerrara la parte monumental del edificio del Ayuntamiento con una verja, con el fin de evitar los destrozos y mutilaciones en su labor escultórica, provocados por actos vandálicos. Tal y como la propia instancia recuerda, hacía años que se había aprobado la colocación de dicha verja, así como su diseño, razón por que la Sociedad apremiaba para que fuera instalada, recomendando mientras tanto que se cuidara la integridad de dicha construcción.

Respecto a la colocación de la verja, es preciso señalar que después de la restauración de la parte monumental del Ayuntamiento, ejecutada por Pedro Domínguez en 1900, este sector fue protegido por una cerca de madera que fue retirada en 1910 por petición del concejal José Sánchez Seco ${ }^{38}$. Ante los continuos atentados contra dicha fachada, se comprende el interés de la Sociedad por que se colocara la verja que había quedado acordada años antes, tal y como señalan en su instancia ${ }^{39}$.

La respuesta de la Alcaldía, previa consulta de la Comisión de Obras Públicas, informaba el 13 de mayo de 1911 a la Sociedad que la recomendación sobre el cuidado del solar de la calle Mármoles quedaba desestimada, "siendo proyecto de esta Corporación municipal trasladar los monolitos romanos que se encuentran enclavados en el solar de la calle Mármoles, a otro lugar más adecuado y en condiciones para que por su instalación puedan ser mejor admirados por propios y extraños". Por otro lado, la resolución de la colocación de la verja quedaba aplazada. No satisfechos con esta respuesta, la Sociedad volvió a dirigir una nueva instancia a la alcaldía el 7 de julio de 1911 en los mismos términos, argumentando con minuciosidad ambas peticiones, a las que añadieron su protesta contra con la decisión tomada.

Fondo Gestoso, Papeles Varios, t. XXXVI, fol. 60-61.

37 A.M.S., C.A. Monolitos, caja 873 (v. 267).

38 A.M.S., Sección X, Actas Capitulares de 1910, 4 de febrero.

${ }^{39}$ La Comisión Provincial de Monumentos había intervenido en 1892 en el diseño de la verja que se había decidido colocar para proteger la fachada monumental del Ayuntamiento, cf. LÓPEZ, Raquel: La Comisión..., op. cit., pp. 111-112. 
Lo cierto es que la petición de la Sociedad no cayó en saco roto, a pesar del aparente desinterés del Ayuntamiento. Las columnas del solar de la calle Mármoles jamás fueron trasladadas del lugar en el que, a día de hoy aún se encuen$\operatorname{tran}^{40}$; la verja del Ayuntamiento finalmente fue colocada, pero después de algún tiempo, en 1918, siendo retirada tan sólo un año después ${ }^{41}$.

Después de la reunión de la junta directiva de la Sociedad del 16 de marzo, de la que acabamos de hacernos eco, no nos consta que se celebrara otra más hasta principios del mes de abril de 1911, en la cual acordaron algunas iniciativas ideadas con el fin de potenciar los valores artísticos y culturales de la Feria de Sevilla. Así, convinieron "ponerse al habla con los presidentes de los casinos y círculos que colocan casetas en la feria, a fin de que por esas corporaciones se propague el uso de la mantilla en las damas (...), gestionar que los caballeros concurran con chaquetilla y sombrero de ala ancha" 42 . No debería extrañarnos el aparente cambio en la hoja de ruta de la Sociedad, puesto que dentro de sus intereses, además de la conservación de los monumentos de Sevilla, recordemos que también existía el interés por proteger "de cuanto en ella [Sevilla] existe de artístico, tradicional, típico o histórico en sus distintas manifestaciones ${ }^{43}$ ", por otro lado, en línea con los postulados del regionalismo cultural que en aquel momento se estaban gestando.

Precisamente el 3 de mayo, se volvió a reunir la junta directiva, acordando dar las gracias a aquellos casinos, círculos y particulares a los que se habían dirigido con anterioridad y que durante la Feria habían organizado fiestas andaluzas. También surgió el interés por fomentar la celebración de las Cruces de Mayo para el año siguiente, organizando para ello concursos con premios. Qué duda cabe que esa predilección por impulsar las costumbres y los festejos locales, estaba en línea con las iniciativas lanzadas para fomentar el desarrollo turístico en España, fuente generadora de grandes ingresos, y que alcanzaron su máxima expresión con la creación en 1911 de la Comisaría Regia de Turismo. Tal y como señala María Luisa Menéndez, "Se alteran las costumbres, que en las zonas más visitadas se fosilizan sólo formalmente para mostrar el tipismo que atrae al turista" 4 .

Por último, otro de los acuerdos de aquel día iba encaminado a realizar las gestiones oportunas con la sevillana Real Academia de Bellas Artes con el fin de que esta "solicitara para el Museo algunos restos artísticos que existen en el

40 Años atrás, en 1877, ya habían intentado trasladarlas para que formaran parte de un monumento a San Fernando, tal y como nos informa GESTOSO Y PÉREZ, José: Sevilla monumental y artística. Sevilla, 1989, vol. I, pp. 26-27.

${ }^{41}$ MORALES MARTÍNEZ, Alfredo: La obra renacentista del Ayuntamiento de Sevilla. Sevilla, 1981, p. 83.

42 Sevilla, 6 de abril de 1911.

${ }^{43}$ El Liberal (Sevilla), 30 de marzo de 1911.

${ }^{44}$ MENÉNDEZ ROBLES, María Luisa: El Marqués de la Vega Inclán y los orígenes del turismo en España. Madrid, 2006, p. 99. 
derruido edificio de San Pablo". Posiblemente se tratara de los azulejos de la escalera del convento de San Pablo, que sólo en parte fueron entregados al Museo de Bellas Artes de Sevilla, pues el expolio y el vandalismo ya habían provocado grandes pérdidas en el conjunto cerámico.

Sin poder asegurar en qué fecha exacta, la Sociedad ejerció de órgano consultor en el proceso de rehabilitación de la Casa de Correos y Telégrafos de Sevi1la, antiguo convento de San Acacio. Dirigida por el arquitecto Luis $\mathrm{M}^{\mathrm{a}}$ Cabello y Lapiedra, la intervención en el ruinoso edificio fue modélica para la época, limitándose tan sólo a las obras de arreglo y reparación necesarias para continuar con su función ${ }^{45}$. Aun así, supieron auxiliar a los técnicos a reformarlo, sin desvirtuar su aspecto original, conservando sus elementos constructivos y decorativos diseñados por Leonardo de Figueroa hacia $1690^{46}$.

Nada más se menciona sobre la Sociedad Defensa de Sevilla Artística desde principios del año 1912, citándose en una publicación de la época su participación en un acto celebrado en el Ateneo de Sevilla en honor de los alumnos de la Escuela Central de Arquitectura de Madrid, y de su profesor y posteriormente director (1920-1923), Vicente Lampérez y Romea ${ }^{47}$. Parece que la actividad de esta sociedad, precursora en Sevilla en la salvaguarda del patrimonio histórico-artístico, no se prolongó en el tiempo tanto como sus miembros fundadores hubieran querido. José Gestoso y Pérez, uno de los miembros más activos de la misma, conservó entre sus papeles personales una de las hojas de adhesión a esta agrupación, como ya hemos señalado. En este documento, el propio Gestoso, escribió "Esta sociedad fué fflor de un día! Apenas si vivió unos meses por la apatía y la indiferencia de quienes debieron velar por su existencia".

En conclusión, tal y como las referencias documentales y hemerográficas demuestran, en este año de 1911 no fueron pocos los monumentos que en Sevilla

${ }^{45}$ Sobre las obras efectuadas en el edificio, A.M.S. C.A. Correos, caja 838 (v.112), "Expediente formado con motivo de las obras de arreglo y reforma de la Casa de Correos y Telégrafos de esta ciudad"; a tenor de los datos proporcionados por la memoria descriptiva y los planos de las obras, la intervención fue muy respetuosa con el edificio, derribándose apenas unos pocos tabiques y la escalera, en estado ruinoso. El propio Cabello era consciente de su importancia monumental: "conserva restos característicos de la arquitectura local de aquella centuria [XVII], siendo el más importante el patio principal que aunque de estilo barroco y decadente, tiene su valor artístico (...) [el edificio] ha sufrido diferentes transformaciones y reformas sin método".

Los resultados fueron difundidos por el propio arquitecto: CABELLO Y LAPIEDRA, Luis $\mathrm{M}^{\mathrm{a}}$.: "La casa de correos y telégrafos en Sevilla", La Ilustración española y americana, n 11, 1913, pp. 24-26; "Los nuevos edificios para Correos y telégrafos" en $\mathrm{Ar}$ quitectura y construcción, 1919, pp. 88-93.

${ }_{46}$ Especialmente el patio, que fue cubierto con una montera de cristal.

47 "Los arquitectos sevillanos y los alumnos de la Escuela central de Arquitectura", La construcción moderna, 15 de enero de 1912, p. 17. 
estuvieron destinados a desaparecer como consecuencia de la negligencia que demostraron las autoridades encargadas de su salvaguarda. A ello habría que sumarle las propuestas urbanísticas de marcado interés por la apertura del viario, centradas en el saneamiento de calles a costa de la demolición del caserío antiguo de la ciudad. Los controvertidos proyectos de ensanche, el abandono de iglesias y la mutilación de las murallas de la Macarena, provocaron un importante conflicto en la opinión pública, fruto de la confrontación de intereses dispares. Las aportaciones de la Sociedad de Defensa de Sevilla Artística, nos han permitido tomar conciencia de esa realidad, valorando sus iniciativas en pos de la protección de la riqueza monumental de la ciudad, algunas de ellas, en línea con planteamientos muy avanzados en materia de tutela del patrimonio cultural.

A pesar de que ya ha pasado más de un siglo desde entonces, en Sevilla se ha repetido y se repite la misma problemática en numerosas ocasiones. No pretendemos dar una visión maniquea del conflicto, presentándolo como un enfrentamiento entre la mentalidad sensible a la conservación e interesada en la salvaguarda de los valores monumentales de la ciudad y el interés por promover un urbanismo acorde con el desarrollo del estilo de vida contemporáneo. Pero qué duda cabe que este planteamiento, forma parte de una realidad palpable dentro de la sociedad sevillana que al igual que en 1911, sigue presente en prensa, foros académicos y otros círculos sociales e intelectuales, donde se ha buscado imponer una u otra postura a costa del rechazo de la opuesta. La solución a estas controversias no se encuentra en las opiniones asentadas sobre dogmas irrenunciables, sino en el debate acerca de cuáles son las prioridades y los verdaderos intereses de una ciudad histórica como Sevilla.

Fecha de recepción: 30 de septiembre de 2015.

Fecha de aceptación: 20 de noviembre de 2015. 


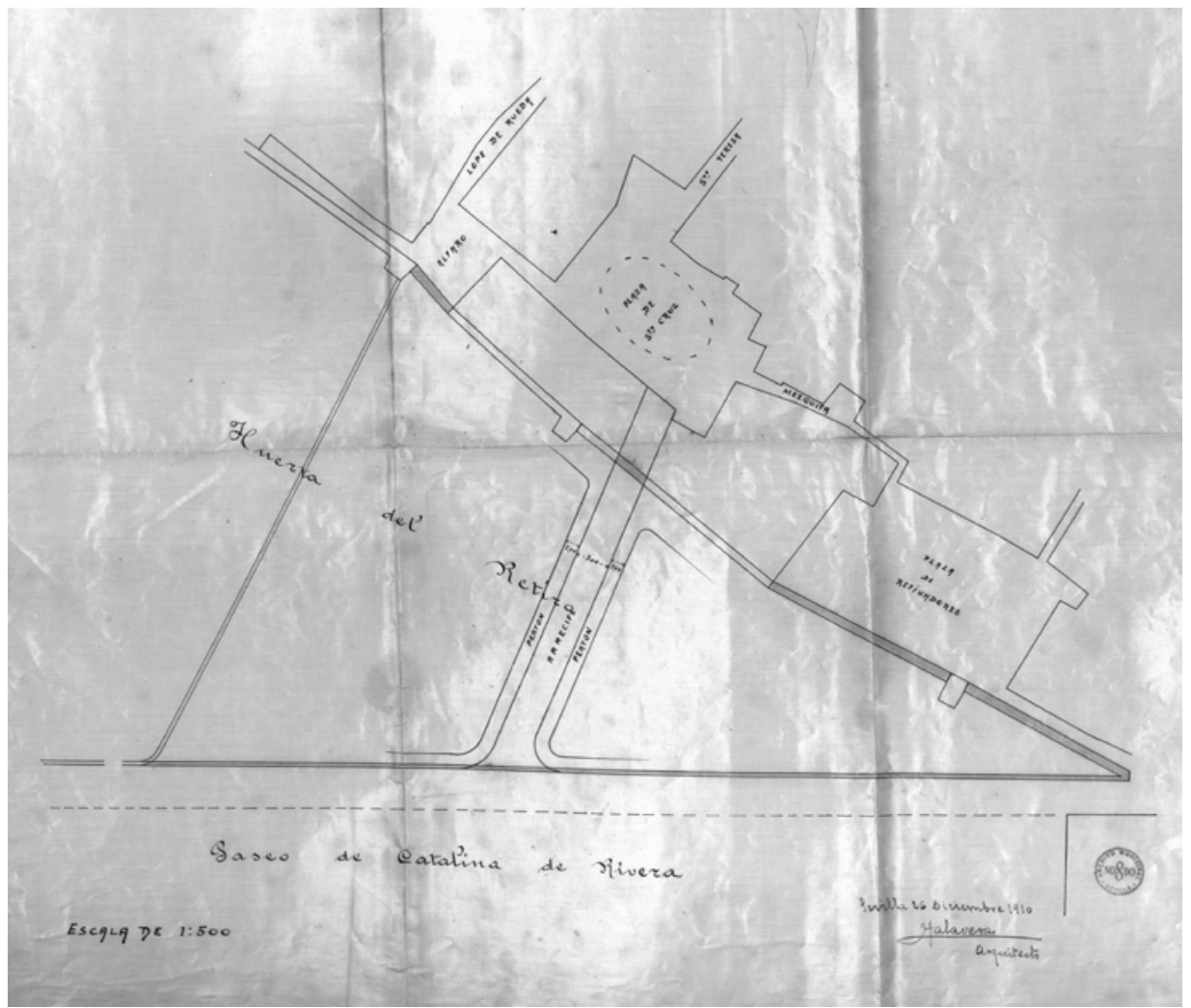

Figura 1. Juan Talavera, Proyecto de alineación para una nueva vía que comunique la plaza de Sta. Cruz con el Prado de San Sebastián, 26 de diciembre de 1910. Archivo Municipal de Sevilla. 